\title{
Transitional dynamics in a Tullock contest with a general cost function
}

\author{
Grossmann, Martin ; Lang, Markus ; Dietl, Helmut
}

\begin{abstract}
This paper constructs and analyzes open-loop equilibria in an infinitely repeated Tullock contest in which two contestants contribute efforts to accumulate individual asset stocks over time. To investigate the transitional dynamics of the contest in the case of a general cost function, we linearize the model around the steady state. Our analysis shows that optimal asset stocks and their speed of convergence to the steady state crucially depend on the elasticity of marginal effort costs, the discount factor and the depreciation rate. In the case of a cost function with a constant elasticity of marginal costs, a lower discount factor, a higher depreciation rate and a lower elasticity imply a higher speed of convergence to the steady state. We further analyze the effects of second prizes in the contest. A higher prize spread increases individual and aggregate asset stocks, but does not alter the balance of the contest in the long run. During the transition, a higher prize spread increases asset stocks, produces a more balanced contest in each period and increases the speed of convergence to the steady state.
\end{abstract}

DOI: https://doi.org/10.2202/1935-1704.1795

Posted at the Zurich Open Repository and Archive, University of Zurich

ZORA URL: https://doi.org/10.5167/uzh-61641

Journal Article

Published Version

Originally published at:

Grossmann, Martin; Lang, Markus; Dietl, Helmut (2011). Transitional dynamics in a Tullock contest with a general cost function. B.E.Journal of Theoretical Economics, 11(1):17.

DOI: https://doi.org/10.2202/1935-1704.1795 


\title{
The B.E. Journal of Theoretical Economics
}

\author{
Topics
}

Volume 11, Issue 1

2011

Article 17

\section{Transitional Dynamics in a Tullock Contest with a General Cost Function}

\author{
Martin Grossmann* \\ Markus Lang $^{\dagger}$ \\ Helmut Dietl ${ }^{\ddagger}$
}

*University of Zurich, martin.grossmann@ @usiness.uzh.ch

†University of Zurich, markus.lang@ business.uzh.ch

‡University of Zurich, helmut.dietl@business.uzh.ch

\section{Recommended Citation}

Martin Grossmann, Markus Lang, and Helmut Dietl (2011) "Transitional Dynamics in a Tullock Contest with a General Cost Function," The B.E. Journal of Theoretical Economics: Vol. 11: Iss. 1 (Topics), Article 17. 


\title{
Transitional Dynamics in a Tullock Contest with a General Cost Function*
}

\author{
Martin Grossmann, Markus Lang, and Helmut Dietl
}

\begin{abstract}
This paper constructs and analyzes open-loop equilibria in an infinitely repeated Tullock contest in which two contestants contribute efforts to accumulate individual asset stocks over time. To investigate the transitional dynamics of the contest in the case of a general cost function, we linearize the model around the steady state. Our analysis shows that optimal asset stocks and their speed of convergence to the steady state crucially depend on the elasticity of marginal effort costs, the discount factor and the depreciation rate. In the case of a cost function with a constant elasticity of marginal costs, a lower discount factor, a higher depreciation rate and a lower elasticity imply a higher speed of convergence to the steady state. We further analyze the effects of second prizes in the contest. A higher prize spread increases individual and aggregate asset stocks, but does not alter the balance of the contest in the long run. During the transition, a higher prize spread increases asset stocks, produces a more balanced contest in each period and increases the speed of convergence to the steady state.
\end{abstract}

KEYWORDS: dynamic contest, transitional dynamics, logit contest, multiple prizes, rent-seeking

${ }^{*}$ Previous versions of this article were presented at the Annual Conference of the Western Economic Association in San Diego and the research seminar of the Institute for Empirical Research in Economics at the University of Zurich. We would like to thank four anonymous referees and the editor who significantly helped us to improve the paper with their detailed and insightful comments and suggestions. Financial support was provided by the Swiss National Science Foundation (Grant No. 100014-120503), the Research Fund of the University of Zurich (Grant No. 53024501) and the Foundation for the Advancement of Young Scientists (FAN) of the Zurcher Universitatsverein (ZUNIV). Responsibility for any errors rests with the authors. 
Grossmann et al.: Transitional Dynamics in a Tullock Contest

\section{Introduction}

Individuals and organizations compete for scarce goods, opportunities, positions, and status. Much of these competitions take the form of contests in which competitors make efforts by investing tangible and intangible resources and are rewarded based on their relative "efforts." In the context of business, for example, employees compete in promotion contests (Rosen, 1986; Bognanno, 2001), firms compete in market share contests (Schmalensee, 1976; Piga, 1998) and R\&D labs compete in patent race contests (Loury, 1970; Taylor, 1995). Competition in the form of contests, however, is not limited to the world of business. Contests can be observed in all fields of social life. Litigation (Wärneryd, 2000; Baye et al., 2005), rent-seeking (Farmer and Pecorino, 1999; Baye and Hoppe, 2003; Grossmann and Dietl, 2011), sport championships (Szymanski, 2003; Dietl et al. 2009), political campaigns (Glazer and Gradstein, 2005; Klumpp and Polborn, 2006), military conflicts (Garfinkel and Skaperdas, 2007), and many other forms of competition take the form of contests. $^{1}$

Such contests are usually modeled as static one-shot games. While this static approach may be sufficient to highlight many important aspects of competition, it ignores the fact that effort decisions in contests are often inter-temporarily connected. The effort invested in today's contest may affect the probability of winning a similar contest tomorrow.

In this paper, we analyze the transitional dynamics in an infinitely repeated Tullock contest between two players with general cost functions. In each period, both contestants simultaneously exert efforts by investing in some form of "asset," such as reputation, human capital, market share, prestige, weapons and so on. This asset stock accumulates over time and, in each period, determines the probability of winning an exogenous first prize (winner) and second prize (loser). We assume that contestants are not able to observe the past actions of their rivals, so that we can analyze open-loop equilibria.

To solve the model with a general cost function, we linearize the accumulation and Euler equations around the steady state. By these means, we are able to investigate the incentives to exert effort close to the steady state. To the best of our knowledge, the linearization procedure has not yet been applied to a Tullock contest model. Our analysis shows that the optimal asset stocks and their speed of convergence crucially depend on the elasticity of marginal effort costs, the discount factor and the depreciation rate. We

\footnotetext{
${ }^{1}$ For a comprehensive survey on contest theory, see Konrad (2009).
} 
further investigate the effects of second prizes in the transition to the steady state as well as in the steady state itself. ${ }^{2}$

Our article contributes to the growing literature on dynamic contests, in particular, on infinitely repeated contests in discrete time. ${ }^{3}$ Infinitely repeated Tullock contests have been studied by Leininger and Yang (1994), Amegashie (2006) and Shaffer and Shogren (2008). Leininger and Yang (1994) study a dynamic Tullock contest with linear effort costs and show that wasteful expenditures in sequential-move games with an infinite time horizon are lower than in static simultaneous-move games. Contrary to Leininger and Yang (1994), our model looks at a sequence of outcomes rather than a single final outcome. Our paper is also related to Shaffer and Shogren (2008), who consider infinitely repeated Tullock contests with linear costs to study the efficiency consequences on regulation and governance. They focus on the question whether more rents are dissipated in repeated regulatory contests than onetime competitions under two equilibrium concepts: Friedman's classic trigger strategy and the Rotemberg and Saloner equilibrium. Similarly, Amegashie (2006) uses the Tullock framework in an infinitely repeated contest with linear effort costs to show that collusion is easier to sustain when the players are more equal than when they are less equal.

Furthermore, Krähmer (2007) analyzes infinitely repeated contests in which the contestants do initially not know their true relative abilities but are able to learn about them over time. He models a general-form, two-player contest in which each contestant can exert either low or high effort and the contestants' win probabilities depend on effort, ability and luck. He finds that a "belief reinforcement effect" is encouraging optimistic contestants and discourages pessimistic contestants in the case that relative ability and effort are complements. Shaffer and Shogren (2009) explore the properties of repeated rent-seeking games in a general parametric framework and study how effort levels are affected by ability, more productive effort and additional players. Finally, Amegashie (2011) studies both finite and infinite period investment-

\footnotetext{
${ }^{2}$ Note that a contest designer might be interested in the overall quality of the contest measured by the level of aggregate efforts. Simultaneously, a balanced contest could be another goal of the designer. For example, in sports, the quality of the contest often improves with increasing competitive balance (Dietl, Lang, Rathke 2011).

${ }^{3}$ For a dynamic model in continuous time, refer to Wirl (1994).
} 
contest games and shows that it is possible for an asset-owner to overinvest in the asset when property rights are incomplete. ${ }^{4}$

In contrast to our paper, none of the above mentioned papers allows efforts or investments to accumulate over time. Allowing that efforts accumulate over time, makes the analysis significantly more complicated. Most closely related to our work is the paper by Grossmann et al. (2010), which analyzes the investment behavior of clubs in a dynamic contest model of a professional team sports league with talent accumulation. The authors focus on linear and quadratic costs as well as on the effect of revenue sharing on competitive balance. Their model shows that revenue sharing decreases competitive balance and the steady state is attained immediately if investment costs for playing talent are linear. Moreover, they find that revenue sharing decreases the speed of convergence to the steady state if investment costs for playing talent are quadratic. In order to derive their results, Grossmann et al. (2010) use a "shooting method" to simulate their model for quadratic costs. In this article, we extend and generalize the model of Grossmann et al. (2010) by assuming a general convex cost function instead of linear and quadratic costs. This generalization of the cost function requires a linearization of the accumulation and Euler equations around the steady state since the "shooting method" is not applicable.

The remainder of this paper is structured as follows. Section 2 introduces the model with its main assumptions, the information structure, the optimality conditions and the steady state. In Section 3, we analyze the transitional dynamics of the model. Section 4 summarizes the main findings and concludes the paper.

\section{Model}

\subsection{Notation and Assumptions}

Consider an infinitely repeated Tullock contest in discrete time with two contestants. In each period $t=0,1, \ldots$, each contestant $i \in\{1,2\}$ chooses a "contribution" $e_{i, t} \in \mathbb{R}_{0}^{+}$to accumulate an asset stock $E_{i, t} \in \mathbb{R}_{0}^{+}$. This asset

\footnotetext{
${ }^{4}$ For dynamic constests that are not infinitely repeated, see, e.g., Gradstein (1998) and Gradstein and Konrad (1999) who study the design of multi-round contests with the elimination of the loser in each round. Moldovanu and Sela (2006) analyze an all-pay auction model of an elimination contest. Furthermore, Gürtler and Münster (2009) study sabotage in a tournament with two rounds. Our paper is also related to Yildirim (2005) who analyzes a two-stage Tullock contest with two players in which a single prize is allocated at the end of the second period. In this model, the players have the possibility of adding to their previous efforts after having observed their rival's most recent efforts.
} 
The B.E. Journal of Theoretical Economics, Vol. 11 [2011], Iss. 1 (Topics), Art. 17

stock can include reputation, human capital, market share, R\&D investments, lobbying activities, prestige, weapons and so on. In the subsequent analysis, we refer to the contribution $e_{i, t}$ as "efforts" as it is customary in the literature on contests.

Efforts are undertaken simultaneously, and the asset stock depreciates over time. The accumulation equation for the asset stock is given by

$$
E_{i, t}=(1-\delta) E_{i, t-1}+e_{i, t}
$$

with $t=0,1, \ldots$ and $i \in\{1,2\}$. Note that $E_{i, t}$ characterizes the state variable in our model. The parameter $\delta \in(0,1)$ represents the depreciation factor. Equation (1) shows that efforts are necessary to maintain the existing asset stock. Before the competition starts, i.e., in period $t=-1$, each contestant $i$ is assumed to have an initial asset stock given by $E_{i,-1} \in \mathbb{R}_{0}^{+}$.

In each period $t$, the available asset stock of contestant $i$ determines which contestant wins the exogenously-given prize fund $V \in \mathbb{R}^{+}$, which is divided between the winner and the loser of the contest. We assume that the winner receives $k V$ and the loser receives $(1-k) V$ with $k \in\left(\frac{1}{2}, 1\right]$. That is, $k$ is the fraction of the prize fund allocated to the first prize and $2 k-1$ characterizes the spread between first and second prize ("prize spread"). ${ }^{5}$ We assume that the contest designer can choose both the prize fund $V$ and the fraction $k$ of the prize fund allocated to the first prize. In the subsequent analysis, it holds that $i, j \in\{1,2\}, j \neq i$ and $t=0,1, \ldots$, unless otherwise stated.

To calculate the probability $p_{i} \in[0,1]$ that contestant $i$ wins the first prize $k V$ in period $t$, we utilize the Tullock contest success function (CSF) which is a widely-used functional form of a CSF in the contest literature. Its general form was introduced by Tullock (1980) and axiomatized by Skaperdas (1996) and Clark and Riis (1998). The Tullock CSF is given by

$$
p_{i}\left(E_{i, t}, E_{j, t}\right)=\left\{\begin{array}{cl}
\frac{E_{i, t}^{\gamma}}{E_{i, t}^{\gamma}+E_{j, t}^{\gamma}}, & \text { if } \max \left\{E_{i, t}, E_{j, t}\right\}>0 \\
\frac{1}{2}, & \text { otherwise. }
\end{array}\right.
$$

If contestant $i$ does not win the first prize, s/he will win the second prize with certainty. Hence, the probability that contestant $i$ wins the second prize $(1-k) V$ is given by $1-p_{i}\left(E_{i, t}, E_{j, t}\right)$. The parameter $\gamma \in \mathbb{R}^{+}$is called

\footnotetext{
${ }^{5}$ See, e.g., Szymanski and Valletti (2005), who model the incentive effects of second prizes in a static game. Unlike Szymanski and Valletti, we consider repeated instead of one-shot contests and we use a general cost function rather than linear costs. For a literature review about multiple-prize contests and the optimal allocation of prizes, see Sisak (2009).
} 
the "discriminatory power" of the CSF and reflects the degree to which the asset stock affects the winning probability. ${ }^{6}$

The ratio of the winning probabilities $p_{i}\left(E_{i, t}, E_{j, t}\right) / p_{j}\left(E_{i, t}, E_{j, t}\right)$ - also called "win ratio" - describes how even the contest is in period $t$. The contest is more balanced if the win ratio gets closer to 1 .

We assume that efforts of contestant $i$ generate costs according to a (strictly) convex cost function $C(e)$ with $C^{\prime}(e)>0$ and $C^{\prime \prime}(e)>0$ for $e>0$ and $C^{\prime}(0)=0$. It should be noted that we concentrate on the effects of asymmetrical initial asset stocks on the optimal effort contributions of contestants over time. That is, we consider contestants with a common, strictly convex cost function but asymmetrical initial asset stocks.

Contestant $i$ 's expected profits $\pi_{i, t}$ in period $t$ are given by expected revenues minus costs:

$$
\pi_{i, t}\left(e_{i, t}, E_{i, t}, E_{j, t}\right)=p_{i}\left(E_{i, t}, E_{j, t}\right) k V+\left[1-p_{i}\left(E_{i, t}, E_{j, t}\right)\right](1-k) V-C\left(e_{i, t}\right)
$$

With probability $p_{i}\left(E_{i t}, E_{j t}\right)$, contestant $i$ receives $k V$, and with probability $1-p_{i}\left(E_{i, t}, E_{j, t}\right) \mathrm{s} /$ he receives $(1-k) V$ at $\operatorname{costs} C\left(e_{i, t}\right)$. Future profits are discounted by a factor $\beta \in(0,1)$. Finally, we assume that the outside option for each contestant is zero.

\subsection{Information and Equilibrium}

In this subsection, we discuss the connection between the information structure and the utilized equilibrium concept. According to Fudenberg and Tirole (1991), if agents (i.e., contestants in our paper) observe their rivals' actions and can condition their action on the history of the game, then the closedloop equilibrium concept is appropriate. If, however, agents only know their previous actions but do not observe the history of their rivals' actions, then the open-loop equilibrium concept is applied. ${ }^{7}$

To solve the model, we follow the approach in Grossmann et al. (2010) and concentrate on open-loop equilibria due to the following two reasons:

1. Real-world examples exist in which agents are unable - at least to some extent - to observe the rivals' actions. For example, suppose that a

\footnotetext{
${ }^{6}$ See, e.g., Dietl et al. (2008) for an analysis of the parameter $\gamma$ in a static contest model. Moreover, Corchón and Dahm (2010) investigate foundations for prominent CSFs.

${ }^{7}$ Open-loop equilibria can also be interpreted as equilibria in which agents commit to their action paths up-front. This pre-commitment implies that agents do not react to possible deviations of the rivals from their equilibrium strategies. We are grateful to an anonymous referee who suggested this point.
} 
The B.E. Journal of Theoretical Economics, Vol. 11 [2011], Iss. 1 (Topics), Art. 17

group lobbies for their individual interests over and over again. This lobbying activity may be hidden such that the open-loop approach is the appropriate equilibrium concept. Another example are pharmaceutical firms that repeatedly compete against each other. These firms invest in R\&D in order to increase their chance to be the first in developing a new medicament. It makes sense to assume that these firms do not know exactly their rivals' specific investment in R\&D such that the open-loop approach is the appropriate equilibrium concept.

2. The open-loop approach ensures tractability. In open-loop equilibria, the strategy space is smaller which facilitates the computation of equilibria, especially in infinitely repeated games. ${ }^{8}$

\subsection{Optimality Conditions and Steady States}

Contestant $i$ maximizes its expected discounted profits $\sum_{t=0}^{\infty} \beta^{t} \pi_{i, t}$ with respect to the stream $\left\{e_{i, t}\right\}_{t=0}^{\infty}$ and subject to the accumulation equation for the asset stock given by equation (1). As shown in Appendix A.1, the Euler equation for contestant $i \in\{1,2\}$ is:

$$
\frac{(2 k-1) V \gamma E_{i, t}^{\gamma-1} E_{j, t}^{\gamma}}{\left(E_{i, t}^{\gamma}+E_{j, t}^{\gamma}\right)^{2}}=C^{\prime}\left(e_{i, t}\right)-\beta(1-\delta) C^{\prime}\left(e_{i, t+1}\right) .
$$

Similar to Grossmann et al. (2010), we establish Proposition 1, which summarizes the steady state results for a general, strictly convex cost function. ${ }^{9}$

Proposition 1 (i) A unique steady state exists, with

$$
E_{i}=E_{j} \equiv E
$$

that is implicitly defined by $(2 k-1) \gamma V /(4 E)=[1-\beta(1-\delta)] C^{\prime}(\delta E)$, and

$$
e_{i}=e_{j} \equiv e
$$

that is implicitly defined by $e=\delta E$.

(ii) The steady state values $E$ and $e$ increase in the prize spread $k$, in the prize fund $V$ and in the discount factor $\beta$.

\footnotetext{
${ }^{8}$ Note that the closed-loop approach can lead to multiple equilibria. For example, Grossmann and Dietl (2009) show in a contest model that multiple equilibria are possible even in a two-period setup.

${ }^{9}$ Henceforth, variables without a time subscript indicate steady states.
} 
(iii) The steady state asset stock $E$ decreases in the depreciation rate $\delta$, while the steady state effort e increases in $\delta$.

Proof. See Appendix A.2.

Part (i) of Proposition 1 shows that efforts and asset stocks are identical for both contestants in the steady state: that is, there is not only a relative convergence but also absolute convergence of the asset stocks in the long run if contestants have identical, strictly convex cost functions. It is important to stress that this result holds even if contestants start with different initial asset stocks $E_{i,-1}$ and $E_{j,-1}$. It immediately follows from part (i) that $p_{i}\left(E_{i}, E_{j}\right)=$ $p_{j}\left(E_{i}, E_{j}\right)=0.5$ holds independently of initial asset stocks. That is, the contest is completely balanced in the long run.

Part (ii) states that the steady state values $E$ and $e$ are increasing in the prize spread and the prize fund due to higher marginal benefits of effort. Therefore, if a contest organizer wants to increase (individual and aggregate) efforts or (individual and aggregate) asset stocks in the long run, it should increase the weight $k$ attached to the first prize and/or increase the prize fund $V$. However, neither the prize spread nor the prize fund affect the balance of the contest in the long run because $p_{i}\left(E_{i}, E_{j}\right)=p_{j}\left(E_{i}, E_{j}\right)$ holds independent of $k$ and $V$. Moreover, we derive that a higher discount factor $\beta$ implies higher asset stocks $E$ in the steady state. Because future expected profits get less discounted, incentives for contestants to exert efforts $e$ are higher such that $E$ increases in $\beta .^{10}$

Part (iii) posits that a higher depreciation rate $\delta$ induces a decrease in steady state asset stocks $E$ since the effect of $E_{i, t}$ upon the future is weaker when $\delta$ is larger. However, a higher $\delta$ increases steady state efforts $e$. Because the depreciation rate decreases steady state asset stocks but increases efforts, a contest designer, who can influence the depreciation rate, cannot maximize both steady state values simultaneously. If, however, the contest designer wants to maximize, for example, only steady state efforts, s/he should ignore previous asset stocks and consider only present efforts to determine who wins the contest. ${ }^{11}$

\footnotetext{
${ }^{10}$ This result may have the following policy implication. In rent-seeking contests, for instance, more forward-looking contestants (higher $\beta$ ) exacerbate social costs. A contest designer therefore should replace contestants frequently to make them less forward-looking.

${ }^{11}$ We are grateful to an anonymous referee for this point.
} 
The B.E. Journal of Theoretical Economics, Vol. 11 [2011], Iss. 1 (Topics), Art. 17

\section{Transitional Dynamics}

\subsection{Approximation Method}

In this section, we investigate the dynamics of the model and analyze the transition (i.e., the short run) to the steady state. According to the accumulation equation (1) and the Euler equation (3), we have a system of non-linear difference equations. It is not possible to solve this model explicitly. In order to obtain a solvable linear system, we must linearize the model around the steady state. This linearization procedure involves two steps. First, we derive the total derivative of equations (1) and (3). Second, we linearize each condition in terms of percentage deviations from the steady state values.

This procedure permits us to approximately determine the optimal path of the asset stocks for both contestants close to the steady state. It has an advantage in that we do not have to specify the cost function, but we are still able to provide an explicit path of the asset stocks. The general drawback of the linearization method is that the results hold only if initial states are close to the steady state. If initial states are not close to the steady state the optimality conditions may not be well represented by the linearized versions of those equations. ${ }^{12}$

\subsection{General Results}

By linearizing the asset stock accumulation equation (1) around the steady state, we obtain: ${ }^{13}$

$$
\hat{E}_{i, t+1}=(1-\delta) \hat{E}_{i, t}+\delta \hat{e}_{i, t+1},
$$

where $\hat{E}_{i, t}=\left(E_{i, t}-E\right) / E$ and $\hat{e}_{i, t}=\left(e_{i, t}-e\right) / e$. Hence, $\hat{E}_{i, t}$ and $\hat{e}_{i, t}$ represents the percentage deviations of $E_{i, t}$ and $e_{i, t}$ from their steady state values $E$ and $e$.

\footnotetext{
${ }^{12}$ For more detail about the linearization method please refer to King et al. (2002), who provide a comprehensive analysis of this method. See also Chamley (1986) and King et al. (1988), who utilize this method to solve dynamic optimization problems.

${ }^{13}$ The total derivative of equation (1) is given by $d E_{i, t+1}=(1-\delta) d E_{i, t}+d e_{i, t+1}$. Because we linearize around the steady state the previous equation becomes $E_{i, t+1}-E=(1-$ $\delta)\left(E_{i, t}-E\right)+e_{i, t+1}-e$ where variables without subscripts represent steady state values. Dividing both sides by $E$ and using the result that $\delta E=e$ in the state steady according to equation (1), we obtain $\left(E_{i, t+1}-E\right) / E=(1-\delta)\left(E_{i, t}-E\right) / E+\left(e_{i, t+1}-e\right) /(e / \delta) \Leftrightarrow$ $\left(E_{i, t+1}-E\right) / E=(1-\delta)\left(E_{i, t}-E\right) / E+\delta\left(e_{i, t+1}-e\right) / e$.
} 
By linearizing the Euler equation (3) around the steady state and using the results from Section 2.3, we obtain: ${ }^{14}$

$$
\hat{E}_{i, t}=\frac{\beta(1-\delta) \sigma(e)}{1-\beta(1-\delta)} \hat{e}_{i, t+1}-\frac{\sigma(e)}{1-\beta(1-\delta)} \hat{e}_{i, t},
$$

where

$$
\sigma(e) \equiv \frac{e C^{\prime \prime}(e)}{C^{\prime}(e)}
$$

is the elasticity of marginal costs with respect to efforts $e$.

Using equations (4) and (5), which hold for contestant $i$ and analogously for contestant $j$, we obtain the following system:

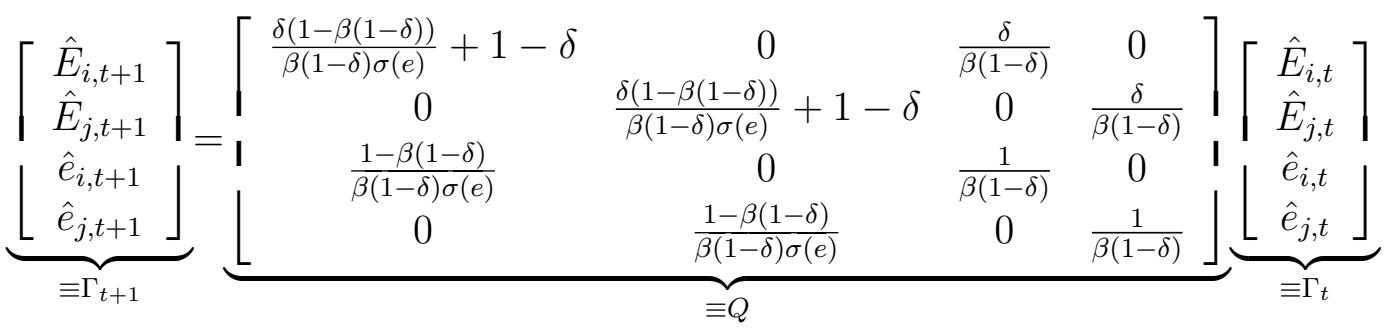

$$
\begin{aligned}
& \Longrightarrow \Gamma_{t+1}=Q \Gamma_{t}
\end{aligned}
$$

Next, we will apply several steps and transform system (7) to derive equations that are necessary to analyze explicitly the optimal dynamics of the asset stocks and efforts. We will show that the stable eigenvalue of the matrix $Q$ will have a decisive influence on the dynamics. The matrix of eigenvalues of $Q$ is defined as follows: ${ }^{15}$

$$
\mu \equiv\left[\begin{array}{cccc}
\mu_{1} & 0 & 0 & 0 \\
0 & \mu_{2} & 0 & 0 \\
0 & 0 & \mu_{3} & 0 \\
0 & 0 & 0 & \mu_{4}
\end{array}\right]
$$

\footnotetext{
${ }^{14}$ Taking total derivative of equation (3) and simplifying yields $-(2 k-1) \gamma V /\left(4 E^{2}\right) d E_{i, t}=$ $C^{\prime \prime}(e) d e_{i, t}-\beta(1-\delta) C^{\prime \prime}(e) d e_{i, t+1}$. Using the fact that $\delta E=e$ and $(2 k-1) \gamma V /(4 E)=(1-$ $\beta(1-\delta)) C^{\prime}(e)$ in the steady state, the previous equation becomes $-(1-\beta(1-\delta)) C^{\prime}(e) \hat{E}_{i, t}=$ $e C^{\prime \prime}(e) \hat{e}_{i, t}-\beta(1-\delta) e C^{\prime \prime}(e) \hat{e}_{i, t+1}$.

${ }^{15}$ Note that $\mu_{\ell}, \ell \in\{1,2,3,4\}$, solves $\operatorname{det}\left(Q-\mu_{\ell} I\right)=0$ with $I$ defined as a $4 \times 4$ identity matrix.
} 
The B.E. Journal of Theoretical Economics, Vol. 11 [2011], Iss. 1 (Topics), Art. 17

where

$$
\begin{aligned}
& \mu_{1}=\mu_{2}=\frac{1}{2} \quad \frac{\delta(1-\beta(1-\delta))}{\beta(1-\delta) \sigma(e)}+\frac{1+\beta(1-\delta)^{2}}{\beta(1-\delta)}-\sqrt{\left(\frac{\delta(1-\beta(1-\delta))}{\beta(1-\delta) \sigma(e)}+\frac{1+\beta(1-\delta)^{2}}{\beta(1-\delta)}\right)^{2}-\frac{4}{\beta}} \\
& \mu_{3}=\mu_{4}=\frac{1}{2} \quad \frac{\delta(1-\beta(1-\delta))}{\beta(1-\delta) \sigma(e)}+\frac{1+\beta(1-\delta)^{2}}{\beta(1-\delta)}+\sqrt{\left(\frac{\delta(1-\beta(1-\delta))}{\beta(1-\delta) \sigma(e)}+\frac{1+\beta(1-\delta)^{2}}{\beta(1-\delta)}\right)^{2}-\frac{4}{\beta}}
\end{aligned}
$$

We conclude that all eigenvalues $\mu_{\ell}, \ell \in\{1,2,3,4\}$ are real. One can further show that the modulus of $\mu_{1}$ and $\mu_{2}$ is smaller than 1 and the modulus of $\mu_{3}$ and $\mu_{4}$ is larger than $1 .{ }^{16}$ It follows that there are two stable eigenvalues $\left(\mu_{1}=\mu_{2}\right)$ and two unstable eigenvalues $\left(\mu_{3}=\mu_{4}\right)$. Henceforth, we will use the parameter $\mu_{s}$ interchangeably for the stable eigenvalues $\mu_{1}$ and $\mu_{2}$.

The matrix of eigenvalues of $Q$ is useful because we obtain the decomposition $Q=P \mu P^{-1}$ where $P$ is defined as the matrix of eigenvectors of $Q .{ }^{17}$ This decomposition can be used to rewrite the system (7) as follows:

$$
\Gamma_{t+1}=Q \Gamma_{t} \Leftrightarrow \underbrace{P^{-1} \Gamma_{t+1}}_{\equiv \tilde{\Gamma}_{t+1}}=\mu \underbrace{P^{-1} \Gamma_{t}}_{\equiv \tilde{\Gamma}_{t}} \Leftrightarrow \tilde{\Gamma}_{t+1}=\mu \tilde{\Gamma}_{t} .
$$

Hence, we have generated canonical variables:

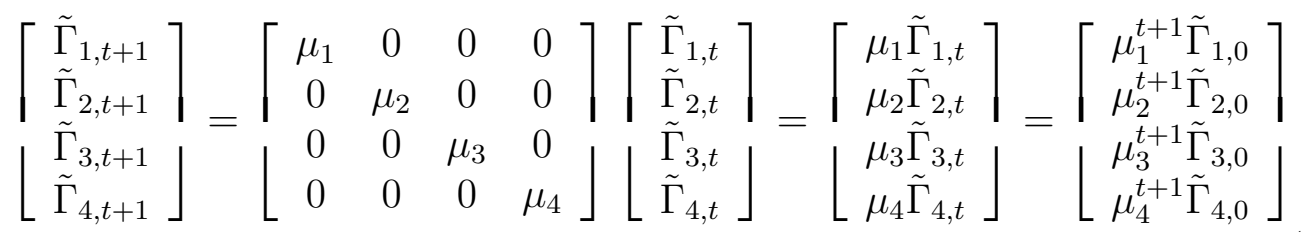

These canonical variables have the advantage that we can determine explicitly the optimal path for the asset stocks and efforts. After some mathematical manipulations, we obtain Proposition 2.

Proposition 2 In the linearized model, a unique solution of contestant efforts and asset stocks exists for all initial asset stocks $\left(E_{1,-1}, E_{2,-1}\right) \in \mathbb{R}_{o}^{+} \times \mathbb{R}_{o}^{+}$. The dynamics of efforts and asset stocks near the steady state for contestant $i \in\{1,2\}$ are summarized by equations

$$
\begin{aligned}
e_{i, t} & =e+\left(\mu_{s}+\delta-1\right)\left(E_{i,-1}-E\right) \mu_{s}^{t}, \\
E_{i, t} & =E+\left(E_{i,-1}-E\right) \mu_{s}^{t+1},
\end{aligned}
$$

\footnotetext{
${ }^{16}$ See Appendix A.3.

${ }^{17}$ See Hamilton (1994) and Greene (2000) for a detailed review of the decomposition procedure.
} 
for $t=0,1, \ldots$, where the stable eigenvalue $\mu_{s} \in(0,1)$ of the linearized system is given by

$$
\begin{aligned}
\mu_{s}= & \frac{1}{2}\left(\frac{\delta(1-\beta(1-\delta))}{\beta(1-\delta) \sigma(e)}+\frac{1+\beta(1-\delta)^{2}}{\beta(1-\delta)}\right) \\
& -\frac{1}{2} \sqrt{\left(\frac{\delta(1-\beta(1-\delta))}{\beta(1-\delta) \sigma(e)}+\frac{1+\beta(1-\delta)^{2}}{\beta(1-\delta)}\right)^{2}-\frac{4}{\beta}}
\end{aligned}
$$

Proof. See Appendix A.4.

The proposition shows that there exists a unique solution of efforts and asset stocks in the linearized model even if contestants have different initial asset stocks: that is, there is a unique path of efforts that is optimal for each contestant. As a result, we are able to negate the possibilities of "multiple equilibria" or "no equilibrium". Moreover, we obtain an explicit optimal path for efforts and asset stocks through the linearization method. The dynamics of the asset stocks crucially depend on the stable eigenvalue $\mu_{s}$ of the linearized system. Based on Proposition 2, we derive the following corollary.

Corollary 1 In the linearized model, the following are true:

(i) Contestant $i$ 's efforts $e_{i, t}$ monotonically increase (decrease) over time into the steady state $e$ if $E_{i,-1}>E\left(E_{i,-1}<E\right)$. Moreover, lower initial asset stocks $E_{i,-1}$ imply higher initial efforts.

(ii) The contestant with the higher initial asset stocks will have a higher probability of winning the prize in the transition.

(iii) The speed of convergence of asset stocks is lower, the higher is the stable eigenvalue $\mu_{s}$ of the linearized system.

Regarding part (i), one can show that $\mu_{s}+\delta-1$ is always smaller than zero. This implies that contestant $i$ 's efforts $e_{i, t}$ monotonically decrease over time into the steady state efforts $e$ if the initial asset stock is smaller than the steady state asset stock, i.e., $E_{i,-1}<E$. Otherwise, if $E_{i,-1}>$ $E$, efforts $e_{i, t}$ monotonically increase over time into steady state efforts $e$. Furthermore, initial asset stocks critically influence the path of efforts and the asset stocks. For instance, suppose that $E_{i,-1}<E$, then a lower value of $E_{i,-1}$ implies higher initial efforts $e_{i, 0}$, ceteris paribus. Part (ii) shows that the contestant with higher initial asset stock always dominates the contest in the transition. ${ }^{18}$ This result follows from equation (10) because the stable eigenvalue is a constant. Regarding part (iii), one can see from equation (10)

\footnotetext{
${ }^{18}$ We would like to thank an anonymous referee who pointed out this result.
} 
that a lower stable eigenvalue $\mu_{s}$ of the linearized system implies a higher speed of convergence of the asset stocks. In particular, the asset stocks immediately converge to the steady state value if the stable eigenvalue converges to zero. ${ }^{19}$

During the transition, the effect of the prize spread on the asset stocks and their speed of convergence is ambiguous for a general convex cost function. The individual and aggregate asset stocks depend on the prize spread because the steady state asset stock $E$ depends on the weight $k$ attached to the first prize (see Section 2.3). Furthermore, the stable eigenvalue $\mu_{s}$ itself depends on (among other parameters) the elasticity of marginal costs $\sigma(e)$. According to Section 2.3, steady state efforts $e$ themselves depend on $k$ as well. Therefore, it is not unambiguous, how the individual as well as aggregate asset stocks depend on the weight $k$ attached to the first prize.

Similarly, for a general convex cost function, it is ambiguous how the elasticity of marginal costs $\sigma(e)$, the discount factor $\beta$ and the depreciation rate $\delta$ affect the stable eigenvalue. It follows that the effect on the speed of convergence of asset stocks is also not clear. To obtain further insights regarding the effects of the different parameters, we analyze a specific class of strictly convex cost functions in the next section.

\subsection{Constant Elasticity of Marginal Costs}

We now analyze the class of cost functions with constant elasticity of marginal $\operatorname{costs} \sigma(e) \equiv \sigma \geq 0$,

$$
C(e)=\frac{\phi}{1+\sigma} e^{1+\sigma}
$$

where $\phi \in \mathbb{R}^{+}$is a parameter. In this case, the stable eigenvalue $\mu_{s} \in(0,1)$ only depends on the parameters $\beta, \delta, \sigma$ and is independent of the weight $k$ attached to the first prize because the elasticity $\sigma$ does no longer depend on steady state efforts $e$.

\subsubsection{Effects of Elasticity of Marginal Costs, Discount Factor and Depreciation Rate}

In this section, we show how the elasticity of marginal costs, the discount factor and the depreciation rate affect the speed of convergence of asset stocks to the steady state. Recall that the stable eigenvalue of the linearized system crucially influences the speed of convergence. In particular, the speed of convergence is lower, the higher is the stable eigenvalue.

\footnotetext{
${ }^{19}$ See Grossmann et al. (2010) who show that linear costs imply immediate convergence of the asset stocks to the steady state.
} 
Computing the partial derivative of the stable eigenvalue with respect to the elasticity $\sigma$ yields

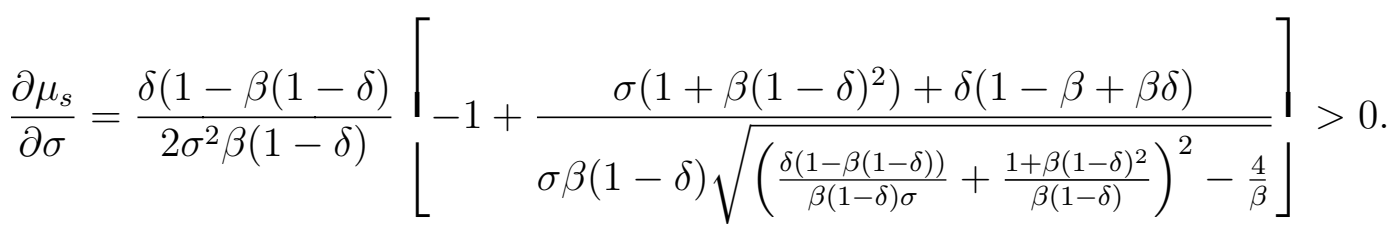

We conclude that a higher elasticity of marginal costs with respect to steady state efforts implies a higher eigenvalue and therefore a lower speed of convergence of the asset stocks. This result holds because a high elasticity implies a more sharply curved cost function which makes it rather profitable to smooth efforts over time. If the elasticity is rather low, high efforts in the beginning of the contest are profitable such that there is lower smoothing behavior over time, and hence, convergence occurs faster. In the limiting case of a linear cost function, the steady state asset stock $E_{i}$ for contestant $i$ would be achieved immediately in the first period independent of initial asset stocks.

How do the other parameters influence the stable eigenvalue of the linearized system and therefore the speed of convergence? We find that a higher discount factor $\beta$ and/or a lower depreciation rate $\delta$ imply a higher eigenvalue, i.e., $\partial \mu_{s} / \partial \beta>0$ and $\partial \mu_{s} / \partial \delta<0$. It follows that a higher $\beta$ yields a lower speed of convergence of the asset stocks. Conversely, the speed of convergence of the asset stocks is higher, the higher is the depreciation rate $\delta$. If the discount factor is low, the future is less important because future expected profits get more discounted and therefore convergence occurs faster. In the limiting case of $\beta=0$, the steady state would be immediately attained in the first period. On the other hand, if the depreciation rate is high, a lower percentage of the current asset stock is taken over to the next period and the speed of convergence is higher. In the limiting case of $\delta=1$, the whole asset stock is depreciated and convergence to the steady state occurs again in the first period.

The following corollary summarizes our results:

Corollary 2 For a cost function with a constant elasticity of marginal costs, the speed of convergence of asset stocks is lower in the linearized model:

(i) the higher is the elasticity of marginal costs, (ii) the higher is the discount factor, and (iii) the lower is the depreciation rate. 
The B.E. Journal of Theoretical Economics, Vol. 11 [2011], Iss. 1 (Topics), Art. 17

\subsubsection{Effect of the Second Prize}

In this section, we investigate the effect of the second prize on the asset stocks and their speed of convergence. First, we analyze how the prize spread affects the asset stocks in the transition. From Section 2.3, we know that a higher weight $k$ attached to the first prize will increase individual asset stocks in the steady state, i.e., $\partial E / \partial k>0$. Therefore,

$$
E_{i, t}=E+\left(E_{i,-1}-E\right) \mu_{s}^{t+1}=E_{i,-1} \mu_{s}^{t+1}+\left(1-\mu_{s}^{t+1}\right) E
$$

is increasing in $k$ because $\partial E_{i, t} / \partial k=\left(1-\mu_{s}^{t+1}\right) \partial E / \partial k>0$. That is, a higher $k$ induces an increase in individual asset stocks during the transition. It follows that also aggregate asset stocks $E_{i, t}+E_{j, t}=\left(E_{i,-1}+E_{j,-1}\right) \mu_{s}^{t+1}+2\left(1-\mu_{s}^{t+1}\right) E$ are increasing in $k$ because $\partial\left(E_{i, t}+E_{j, t}\right) / \partial k=2\left(1-\mu_{s}^{t+1}\right) \partial E / \partial k>0$.

In a further step, we can show that the contest becomes more balanced in each period if the weight $k$ attached to the first prize increases:

$$
\begin{aligned}
\frac{\partial\left(\frac{p_{i, t}}{p_{j, t}}\right)}{\partial k}= & \gamma\left(\frac{E+\left(E_{i,-1}-E\right) \mu_{s}^{t+1}}{E+\left(E_{j,-1}-E\right) \mu_{s}^{t+1}}\right)^{\gamma-1} \frac{\left(1-\mu_{s}^{t+1}\right) \mu_{s}^{t+1}\left(E_{j,-1}-E_{i,-1}\right) \frac{\partial E}{\partial k}}{\left(E+\left(E_{j,-1}-E\right) \mu_{s}^{t+1}\right)^{2}} \\
& \Longrightarrow \frac{\partial\left(\frac{p_{i, t}}{p_{j, t}}\right)}{\partial k}\left\{\begin{array}{l}
>0 \text { if } E_{j,-1}>E_{i,-1} \\
=0 \text { if } E_{j,-1}=E_{i,-1} \\
<0 \text { if } E_{j,-1}<E_{i,-1}
\end{array}\right.
\end{aligned}
$$

From the above calculations, we derive the following results:

- If $E_{j,-1}<E_{i,-1}$, then $p_{i, t} / p_{j, t}>1$ and $\partial\left(p_{i, t} / p_{j, t}\right) / \partial k<0$ : hence, the balance of the contest is increasing in $k$.

- If $E_{j,-1}>E_{i,-1}$, then $p_{i, t} / p_{j, t}<1$ and $\partial\left(p_{i, t} / p_{j, t}\right) / \partial k>0$ : hence, the balance of the contest is increasing in $k$.

- If $E_{j,-1}=E_{i,-1}$, then $p_{i, t} / p_{j, t}=1$ and $\partial\left(p_{i, t} / p_{j, t}\right) / \partial k=0$ : hence, the balance of the contest is not affected by changing $k$.

We conclude that a higher $k$ produces a more balanced contest in each period and therefore it also increases the speed of convergence to the steady state as long as contestants start with different initial asset stocks. These results lead to Corollary 3, which summarizes our key findings. 
Corollary 3 For a cost function with a constant elasticity of marginal costs, in the linearized model, a higher weight $k$ attached to the first prize will:

(i) increase individual asset stocks as well as aggregate asset stocks during the transition as well as in the steady state itself,

(ii) produce a more balanced contest in each period and, therefore, the speed of convergence to the steady state is faster as long as contestants start with different initial asset stocks.

It should be noted that parts (i) and (ii) of Corollary 3 generally hold in the linearized model for a cost function with a constant elasticity of marginal costs. According to the corollary, there are two reasons for a contest designer to increase the prize spread between first and second prize in the case of a cost function with a constant elasticity of marginal costs. First, if the contest designer aims to increase individual and aggregate asset stocks during the transition as well as in the steady state (see Section 2.3) itself, s/he should augment the spread between first and second prize because incentives to exert efforts increase in each period. Second, a higher prize spread increases the balance of the contest in each period during the transition if the contestants start with different initial asset stocks. ${ }^{20} \mathrm{~A}$ contest designer might prefer a balanced contest. For example, in sports, a contest rather gains attention when the outcome is uncertain. In this case, a contest designer can increase the speed of achieving a balanced contest by increasing the weight attached to the first prize. In any case, a fully balanced contest is achieved in the long run (steady state) independent of the organizer's choice of the spread between first and second prize.

\section{Conclusion}

This paper develops an infinitely-repeated Tullock contest with a general cost function, in which two contestants contribute efforts to accumulate individual asset stocks. To investigate the transitional dynamics of the contest, we use an open-loop equilibrium concept and we linearize the model around the steady state. This linearization procedure, which has not yet been applied to a Tullock contest model, permits us to approximately determine the optimal path of asset stocks for both contestants.

Our analysis shows that in the long run (steady state), efforts and asset stocks increase with a higher discount factor. A higher depreciation rate

\footnotetext{
${ }^{20}$ If contestants start with the same asset stocks, then it is clear that asset stocks are balanced in each period.
} 
The B.E. Journal of Theoretical Economics, Vol. 11 [2011], Iss. 1 (Topics), Art. 17

induces a decrease in steady state asset stocks but an increase in the steady state efforts. Our model further shows that optimal effort levels and their speed of convergence to the steady state depend on the stable eigenvalue of the linearized system. In particular, the speed of convergence to the steady state increases if the stable eigenvalue decreases. We further find that the contestants' efforts monotonically increase (decrease) over time into the steady state efforts if initial assets stocks are larger (smaller) than the steady state asset stocks. Moreover, the contestant with the higher initial asset stocks has a higher winning probability in the transition.

In the case of a cost function with a constant elasticity of marginal costs, a lower elasticity, a lower discount factor and a higher depreciation rate imply a lower eigenvalue and therefore induce a faster convergence. Our analysis further reveals that a higher spread between first and second prize increases aggregate asset stocks but does not alter the balance of the contest in the long run. During the transition, a higher prize spread increases the effort contributions of contestants as well as the balance of the contest in each period such that the speed of convergence to the steady state increases.

Our study can be seen as a first step to elucidate the transitional dynamics in an infinitely repeated Tullock contest with multiple prizes and a general cost function. There is a broad range for further applications and model extensions. For example, a promising avenue for further research might be the extension of our model to more than two contestants. Furthermore, it would be interesting to see how our results carry over to a setting in which contestants have different abilities and/or are able to observe the opponents' effort levels after each period (closed-loop concept).

\section{A Appendix}

\section{A.1 Derivation of the Euler Equation}

Similar to Grossmann et al. (2010), we solve the dynamic program for contestant $i$ and obtain:

$$
\begin{aligned}
v\left(E_{i, t-1}\right)= & \max _{\left(e_{i, t}, E_{i, t}\right)}\left\{p_{i}\left(E_{i, t}, E_{j, t}\right) k V+\left(1-p_{i}\left(E_{i, t}, E_{j, t}\right)\right)(1-k) V\right. \\
& \left.-C\left(e_{i, t}\right)+\beta v\left(E_{i, t}\right)\right\} \\
\text { subject to } E_{i, t}= & (1-\delta) E_{i, t-1}+e_{i, t},
\end{aligned}
$$

where $v(\cdot)$ represents the contestants' value function. It is important to highlight that contestant $i$ takes $E_{j, t}$ as given in period $t=0,1, \ldots$ according to 
the open-loop concept. The Lagrangian $L$ with multiplier $\lambda_{t} \in \mathbb{R}_{0}^{+}$of the maximization problem is defined as:

$$
L=\frac{k V E_{i, t}^{\gamma}+(1-k) V E_{j, t}^{\gamma}}{E_{i, t}^{\gamma}+E_{j, t}^{\gamma}}-C\left(e_{i, t}\right)+\beta v\left(E_{i, t}\right)+\lambda_{t}\left[(1-\delta) E_{i, t-1}+e_{i, t}-E_{i, t}\right] .
$$

Maximizing $L$ with respect to $E_{i, t}, e_{i t}$ and $\lambda_{t}$ yields the following firstorder conditions:

$$
\begin{aligned}
C^{\prime}\left(e_{i, t}\right) & =\lambda_{t} \\
\frac{k V \gamma E_{i, t}^{\gamma-1} E_{j, t}^{\gamma}-(1-k) V \gamma E_{i, t}^{\gamma-1} E_{j, t}^{\gamma}}{\left(E_{i, t}^{\gamma}+E_{j, t}^{\gamma}\right)^{2}}+\beta \frac{\partial v\left(E_{i, t}\right)}{\partial E_{i, t}} & =\lambda_{t} \\
(1-\delta) E_{i, t-1}+e_{i, t} & =E_{i, t} .
\end{aligned}
$$

By using the first-order conditions and the envelope theorem $\frac{\partial v\left(E_{i, t-1}\right)}{\partial E_{i, t-1}}=$ $\lambda_{t}(1-\delta)$, we obtain the following Euler equation for contestant $i$ :

$$
\frac{(2 k-1) V \gamma E_{i, t}^{\gamma-1} E_{j, t}^{\gamma}}{\left(E_{i, t}^{\gamma}+E_{j, t}^{\gamma}\right)^{2}}=C^{\prime}\left(e_{i, t}\right)-\beta(1-\delta) C^{\prime}\left(e_{i, t+1}\right) .
$$

\section{A.2 Proof of Proposition 1}

Part (i): Similar to Grossmann et al. (2010), it is easy to show by contradiction that $E_{i}=E_{j} \equiv E$ (implicitly defined by $(2 k-1) \gamma V /(4 E)=$ $\left.[1-\beta(1-\delta)] C^{\prime}(\delta E)\right)$ in the steady state independent of initial asset stocks. Because $(2 k-1) \gamma V /(4 E)$ is decreasing in $E$ and $[1-\beta(1-\delta)] C^{\prime}(\delta E)$ is increasing in $E$, a unique solution exists for the steady state asset stocks $E$. Moreover, $e_{i}=\delta E_{i}$ and $e_{j}=\delta E_{j}$ imply $e_{i}=e_{j}=e=\delta E$.

Parts (ii) and (iii): To prove the comparative statics results, we use the implicit function theorem and obtain

$$
\begin{aligned}
\frac{\partial E}{\partial k} & =-\frac{V \frac{\gamma}{2 E}}{-(2 k-1) V \frac{\gamma}{4 E^{2}}-(1-\beta(1-\delta)) C^{\prime \prime}(\delta E) \delta}>0 \\
\frac{\partial e}{\partial k} & =-\frac{V \frac{\delta \gamma}{2 e}}{-(2 k-1) V \frac{\delta \gamma}{4 e^{2}}-(1-\beta(1-\delta)) C^{\prime \prime}(e)}>0 .
\end{aligned}
$$

Therefore, the steady state values $E$ and $e$ are increasing in $k$. Analogously, it is easy to show that $\partial E / \partial V>0, \partial E / \partial \beta>0, \partial e / \partial V>0, \partial e / \partial \beta>0$ and $\partial E / \partial \delta<0, \partial e / \partial \delta>0$ (see also Grossmann et al., 2010). 
The B.E. Journal of Theoretical Economics, Vol. 11 [2011], Iss. 1 (Topics), Art. 17

\section{A.3 Stable and Unstable Eigenvalues of Matrix Q}

To show that the modulus of $\mu_{1}$ and $\mu_{2}$ is smaller than 1 and the modulus of

$\mu_{3}$ and $\mu_{4}$ is larger than 1 , we analyze the sum and the product of the two different eigenvalues:

$$
\begin{gathered}
\mu_{1}+\mu_{3}=\mu_{2}+\mu_{4}=\frac{\delta(1-\beta(1-\delta))}{\beta(1-\delta) \sigma(e)}+\frac{1+\beta(1-\delta)^{2}}{\beta(1-\delta)}, \\
\mu_{1} \cdot \mu_{3}=\mu_{2} \cdot \mu_{4}=\frac{1}{\beta} .
\end{gathered}
$$

It is easy to see that $\mu_{1}+\mu_{2}>0$ and $\mu_{1} \cdot \mu_{2}>0$. Hence, equation (11) together with equation (12) imply that $\mu_{1}$ and $\mu_{3}$ are both positive roots. We use this intermediate result further below. Figure 1 graphically illustrates equations (11) and (12).

Figure 1: Stable and Unstable Roots

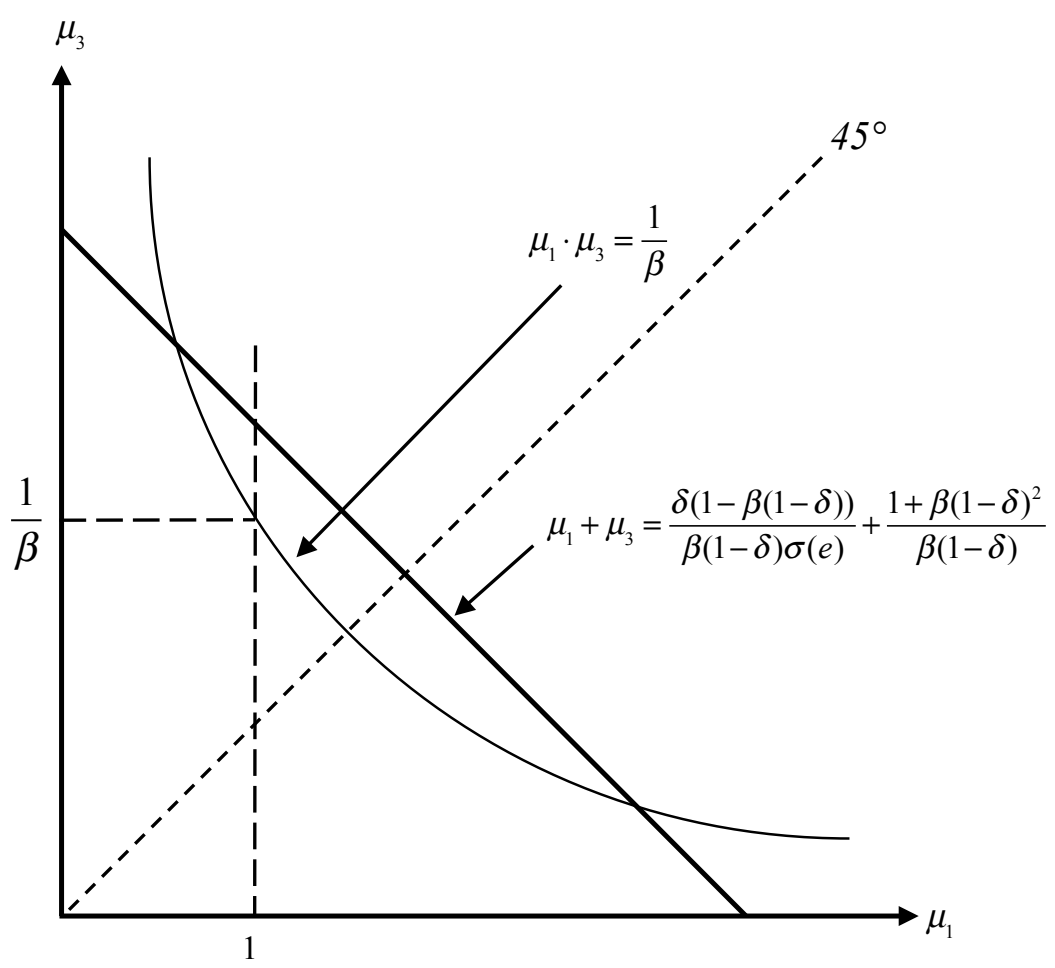


Without loss of generality, we assume that $\mu_{3}>\mu_{1}$. Suppose that $\mu_{1}=1$. It follows from equation (12) that $\mu_{3}=1 / \beta>1$. Furthermore, $\mu_{1}+\mu_{3}=(1+\beta) / \beta$. However, we also know from equation (11) that $\mu_{1}+\mu_{3}=$ $\delta(1-\beta(1-\delta)) /(\beta(1-\delta) \sigma(e))+\left(1+\beta(1-\delta)^{2}\right) /(\beta(1-\delta))$. Hence, we suggest by inspecting Figure 1 that $\mu_{1}<1$ (and therefore $\mu_{3}>1$ ) if and only if the following condition is satisfied:

$$
\frac{1+\beta}{\beta}<\frac{\delta(1-\beta(1-\delta))}{\beta(1-\delta) \sigma(e)}+\frac{1+\beta(1-\delta)^{2}}{\beta(1-\delta)} \Longleftrightarrow 1>-\sigma(e) .
$$

Since effort costs are strictly convex we know that $\sigma(e)>0$. Therefore, inequality (13) is always fulfilled. We conclude that there are two stable roots $\left(\mu_{1}=\mu_{2}\right)$ and two unstable roots $\left(\mu_{3}=\mu_{4}\right)$.

\section{A.4 Proof of Proposition 2}

Because $\left|\mu_{1}\right|<1,\left|\mu_{2}\right|<1,\left|\mu_{3}\right|>1$ and $\left|\mu_{4}\right|>1$, we conclude that $\tilde{\Gamma}_{3,0}$ and $\tilde{\Gamma}_{4,0}$ must be zero to satisfy the transversality condition. ${ }^{21}$ Next, we are able to solve for the original variables $\Gamma_{1,0}$ and $\Gamma_{2,0}$ as follows:

$$
\begin{aligned}
& \Gamma_{0}=P \tilde{\Gamma}_{0}
\end{aligned}
$$

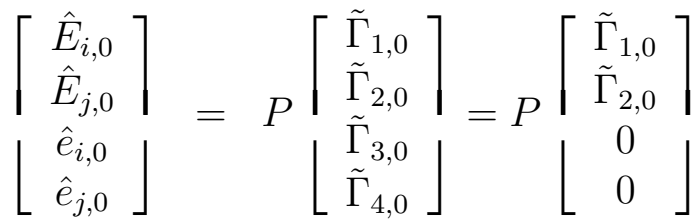

Hence, we obtain a system of four equations with four unknowns $\hat{e}_{i, 0}, \hat{e}_{j, 0}, \tilde{\Gamma}_{1,0}$ and $\tilde{\Gamma}_{2,0}$. Note that $\hat{E}_{i, 0}$ and $\hat{E}_{j, 0}$ are determined by $E_{i,-1}, E_{j,-1}, \hat{e}_{i, 0}$ and $\hat{e}_{j, 0}$. In particular, this computation determines the unique optimal time path of asset stocks and efforts.

Since $\tilde{\Gamma}_{3,0}=\tilde{\Gamma}_{4,0}=0$, equation (8) implies $^{22}$

$$
\hat{\Gamma}_{t}=\mu_{s}^{t} \hat{\Gamma}_{0}
$$

\footnotetext{
${ }^{21}$ The transversality condition in our model is different from the associated condition in standard growth models. In those models, there must be zero capital in the long run: see, e.g., King et al. (1988). In our model, contestants have the following restriction: ex ante, expected profits must be positive for both contestants. Otherwise, it is not optimal for contestants to participate in the contest.

${ }^{22}$ We are grateful to the editor who suggested this shortcut of proving the result.
} 
The B.E. Journal of Theoretical Economics, Vol. 11 [2011], Iss. 1 (Topics), Art. 17

Substituting this equation into the definition of $\Gamma_{t}$, we receive

$$
\Gamma_{t}=P \hat{\Gamma}_{t}=P \mu_{s}^{t} \hat{\Gamma}_{0}=\mu_{s}^{t} P \hat{\Gamma}_{0}=\mu_{s}^{t} \Gamma_{0} .
$$

According to the last equation, we solve for $\hat{E}_{i, t}$ and obtain

$$
\hat{E}_{i, t}=\mu_{s}^{t} \hat{E}_{i, 0}=\mu_{s}^{t+1} \hat{E}_{i,-1}
$$

Hence,

$$
E_{i, t}-E=\mu_{s}^{t+1}\left(E_{i,-1}-E\right) .
$$

The last equation determines the dynamics of the asset stock as suggested in Proposition 2.

In the last step, we consider the dynamics of the optimal policy function $e_{t}$. From the linearization around the steady state, we know that

$$
\begin{aligned}
\hat{E}_{i, t+1} & =(1-\delta) \hat{E}_{i, t}+\delta \hat{e}_{i, t+1} \\
& \Longleftrightarrow E_{i, t+1}-E=(1-\delta)\left(E_{i, t}-E\right)+\left(e_{i, t+1}-e\right) .
\end{aligned}
$$

As $E_{i, t+1}-E=\mu_{s}\left(E_{i, t}-E\right)$, we obtain:

$$
\begin{aligned}
\mu_{s}\left(E_{i, t}-E\right) & =(1-\delta)\left(E_{i, t}-E\right)+\left(e_{i, t+1}-e\right) \\
& \Longleftrightarrow e_{i, t+1}=e+\left(\mu_{s}+\delta-1\right) \mu_{s}^{t+1}\left(E_{i,-1}-E\right) \\
& \Longleftrightarrow e_{i, t}=e+\left(\mu_{s}+\delta-1\right)\left(E_{i,-1}-E\right) \mu_{s}^{t} .
\end{aligned}
$$

This completes the proof.

\section{References}

Amegashie, J. A. (2006), 'Asymmetry and Collusion in Infinitely Repeated Contests', University of Guelph, Department of Economics Working Papers Series Nr. 0509.

Amegashie, J. A. (2011), 'Incomplete Property Rights and Overinvestment', Social Choice and Welfare 37, 81-95.

Baye, M. and Hoppe, H. (2003), 'The Strategic Equivalence of Rent-seeking, Innovation, and Patent-race Games', Games and Economic Behavior 44(2), 217-226. 
Baye, M., Kovenock, D. and Casper, G. (2005), 'Comparative Analysis of Litigation Systems: An Auction-theoretic Approach', Economic Journal 115, 583-601.

Bognanno, M. L. (2001), 'Corporate Tournaments', Journal of Labor Economics 19(2), 290-315.

Chamley, C. (1986), 'Optimal Taxation of Capital Income in General Equilibrium with Infinite Lives', Econometrica 54, 607-622.

Clark, D. and Riis, C. (1998), 'Contest Success Functions: An Extension', Economic Theory 11, 201-204.

Corchón, L. and Dahm, M. (2010), 'Foundations for Contest Success Functions', Economic Theory 43(1), 81-98.

Dietl, H., Franck, E. and Lang, M. (2008), 'Overinvestment in Team Sports Leagues: A Contest Theory Model', Scottish Journal of Political Economy $\mathbf{5 5}(3), 353-368$.

Dietl, H., Lang, M. and Rathke, A. (2011), 'The Combined Effect of Salary Restrictions and Revenue Sharing in Sports Leagues', Economic Inquiry 49(2), 447-463.

Dietl, H., Lang, M. and Werner, S. (2009), 'Social Welfare in Sports Leagues with Profit-Maximizing and/or Win-Maximizing Clubs', Southern Economic Journal 76(2), 375-396.

Farmer, A. and Pecorino, P. (1999), 'Legal Expenditure as a Rent-seeking Game', Public Choice 100(3), 271-288.

Fudenberg, D. and Tirole, J. (1991), Game Theory, MIT Press, Cambridge, Massachusetts.

Garfinkel, M. R. and Skaperdas, S. (2007), Economics of Conflict: An Overview, in T. Sandler and K. Hartley, eds, 'Handbook of Defense Economics - Defense in a Globalized World', Elsevier, Amsterdam, pp. 649709 .

Glazer, A. and Gradstein, M. (2005), 'Elections with Contribution-maximizing Candidates', Public Choice 122(3), 467-482. 
The B.E. Journal of Theoretical Economics, Vol. 11 [2011], Iss. 1 (Topics), Art. 17

Gradstein, M. (1998), 'Optimal Contest Design: Volume and Timing of Rent Seeking in Contests', European Journal of Political Economy 14(4), 575585.

Gradstein, M. and Konrad, K. A. (1999), 'Orchestrating Rent Seeking Contests', Economic Journal 109, 536-545.

Greene, W. (2000), Econometric Analysis, Prentice Hall, New Jersey.

Grossmann, M. and Dietl, H. (2009), 'Investment Behaviour in a Two Period Contest Model', Journal of Institutional and Theoretical Economics 165(3), 401-417.

Grossmann, M., Dietl, H. and Lang, M. (2010), 'Revenue Sharing and Competitive Balance in a Dynamic Contest Model', Review of Industrial Organization 36(1), 17-36.

Grossmann, M. and Dietl, H. M. (2011), 'Asymmetric Contests with Liquidity Constraints', Public Choice (forthcoming).

Gürtler, O. and Münster, J. (2009), 'Sabotage in Dynamic Tournaments', Journal of Mathematical Economics 46(2), 179-190.

Hamilton, J. (1994), Time Series Analysis, Princeton University Press, Princeton, New Jersey.

King, R. G., Plosser, C. I. and Rebelo, S. T. (1988), 'Production, Growth and Business Cycles: I. The Basic Neoclassical Model', Journal of Monetary Economics 21, 195-232.

King, R. G., Plosser, C. I. and Rebelo, S. T. (2002), 'Production, Growth and Business Cycles: Technical Appendix', Computational Economics 20(1), 87-116.

Klumpp, T. and Polborn, M. K. (2006), 'Primaries and the New Hampshire effect', Journal of Public Economics 90, 1073-1114.

Konrad, K. (2009), Strategy and Dynamics in Contests, Oxford University Press, Oxford, UK.

Krähmer, D. (2007), 'Equilibrium Learning in Simple Contests', Games and Economic Behavior 59(1), 105-131. 
Leininger, W. and Yang, C. L. (1994), 'Dynamic Rent-seeking Games', Games and Economic Behavior 7(3), 406-427.

Loury, G. C. (1979), 'Market Structure and Innovation', Quarterly Journal of Economics 13, 395-410.

Moldovanu, B. and Sela, A. (2006), 'Contest Architecture', Journal of Economic Theory 126(1), 70-96.

Piga, C. A. (1998), 'A Dynamic Model of Advertising and Product Differentiation', Review of Industrial Organization 13(5), 509-522.

Rosen, S. (1986), 'Prizes and Incentives in Elimination Tournaments', American Economic Review 76, 701-715.

Schmalensee, R. (1976), 'A Model of Promotional Competition in Oligopoly', Review of Economic Studies 43, 493-507.

Shaffer, S. and Shogren, J. (2008), 'Infinitely Repeated Contests: How Strategic Interaction Affects the Efficiency of Governance', Regulation and Governance 2(2), 234-252.

Shaffer, S. and Shogren, J. F. (2009), 'Repeated Contests: A General Parameterization', Economics Letters 105(2), 159-161.

Sisak, D. (2009), 'Multiple-Prize Contests - the Optimal Allocation of Prizes', Journal of Economic Surveys 23(1), 82-114.

Skaperdas, S. (1996), 'Contest Success Functions', Economic Theory 7, 283290.

Szymanski, S. (2003), 'The Economic Design of Sporting Contests', Journal of Economic Literature 41, 1137-1187.

Szymanski, S. and Valletti, T. M. (2005), 'Incentive Effects of Second Prizes', European Journal of Political Economy 21(2), 467-481.

Taylor, C. R. (1995), 'Digging for Golden Carrots: An Analysis of Research Tournaments', American Economic Review 85, 872-890.

Tullock, G. (1980), Efficient Rent-Seeking, in J. M. Buchanan, R. D. Tollison and G. Tullock, eds, 'Toward a Theory of the Rent Seeking Society', University Press, Texas, pp. 97-112. 
The B.E. Journal of Theoretical Economics, Vol. 11 [2011], Iss. 1 (Topics), Art. 17

Wärneryd, K. (2000), 'In Defense of Lawyers: Moral Hazard as an Aid to Cooperation', Games and Economic Behavior 33(1), 145-158.

Wirl, F. (1994), 'The Dynamics of Lobbying - A Differential Game', Public Choice 80(3), 307-323.

Yildirim, H. (2005), 'Contests with Multiple Rounds', Games and Economic Behavior 51(1), 213-227. 